\title{
A pinkish nodule on the vertex: What's your diagnosis?
}

\author{
Mohamed Ben Rejeb', Yosra Soua', Nouha Abdejlii², Monia Youssef ${ }^{1}$ \\ ${ }^{1}$ Department of Dermatology, Fattouma Bourguiba University Hospital, Monastir-Tunisia, ${ }^{2}$ Department of Anapathology, \\ Fattouma Bourguiba University Hospital, Monastir-Tunisia
}

Corresponding author: Dr. Mohamed Ben Rejeb, E-mail: med.benrejeb@gmail.com

\section{CASE REPORT}

A 71-year-old man presented to our dermatology department with a slightly painful nodular lesion over the scalp for 1 year. The size of the nodule had gradually increased recently. He had no personal or family history of skin disease or other systemic disorders. Cutaneous examination showed well-circumscribed and tender sessile pinkish nodule measuring $2 \mathrm{~cm}$ over the vertex of the scalp (Fig. 1). It was firm in consistency and we noticed an infiltrated area surrounding the lesion. Dermoscopic examination showed a well-defined nodule composed of white structures, pinkish and yellowish homogeneous areas, linear irregular vessels and arborizing telangiectasias (Figs. 2 and 3). The lesion was completely excised.

\section{HISTOLPATHOLOGY}

Histopathological examination showed wellcircumscribed intradermal tumor with a lobular arrangement of uniform and clear cells, ductal structures, and cystic spaces (Figs. 4 and 5).

\section{WHAT'S YOUR DIAGNOSIS?}

\section{Answer: Nodular Hidradenoma}

Nodular Hidradenoma (NH) is a rare benign adnexal neoplasm of either eccrine or apocrine differentiation from sweat glands that is commoner in adults than in children $[1,2]$. It's a challenging diagnosis because of clinical heterogeneity. $\mathrm{NH}$ is more commonly seen in women with an average age of 30 to 40 years. The most common site is the head [3]. Clinically, NH usually

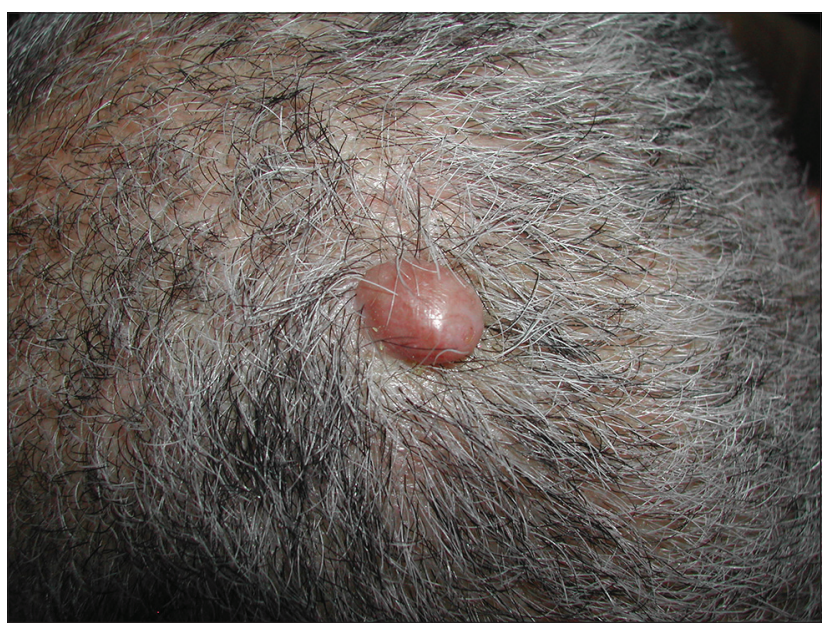

Figure 1: A well-demarked and firm, exophytic pinkish nodule measuring $2 \mathrm{~cm}$ over the vertex of the scalp.

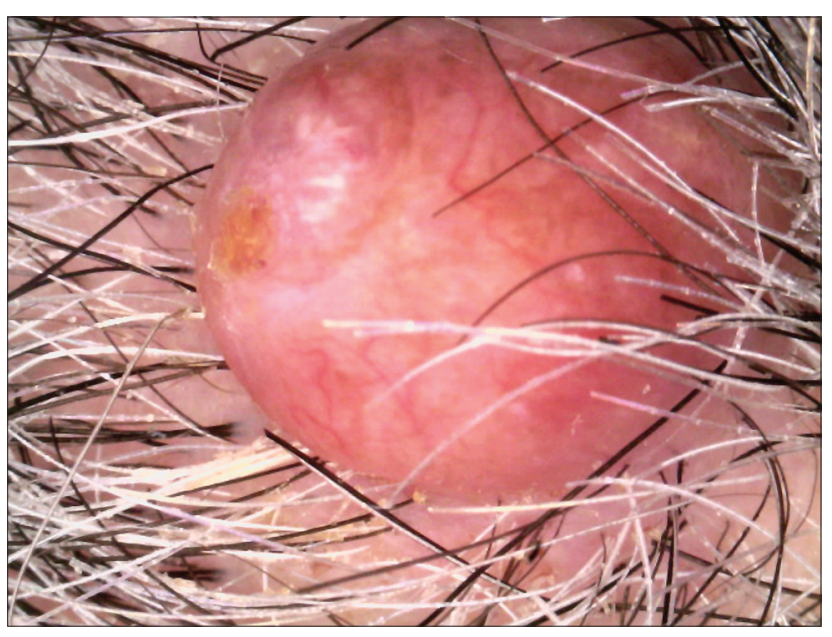

Figure 2: Dermoscopy image of nodular hidradenoma. Note white structures $\left({ }^{*}\right)$, pinkish and yellowish homogeneous areas(\#), linear irregular vessels and arborizing telangiectasias $(\rightarrow)$.

presents as a solitary slow-growing pinkish nodule which is well-circumscribed, firm, non-tender and

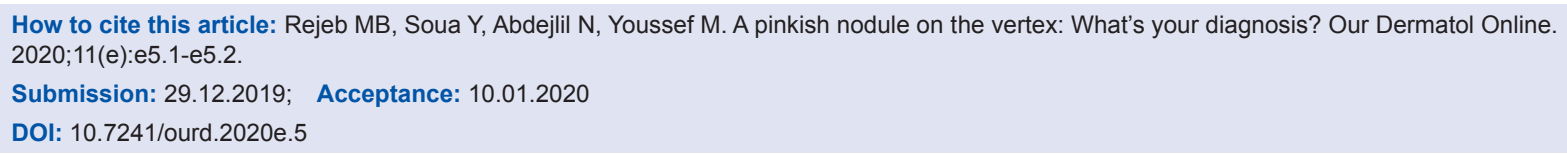




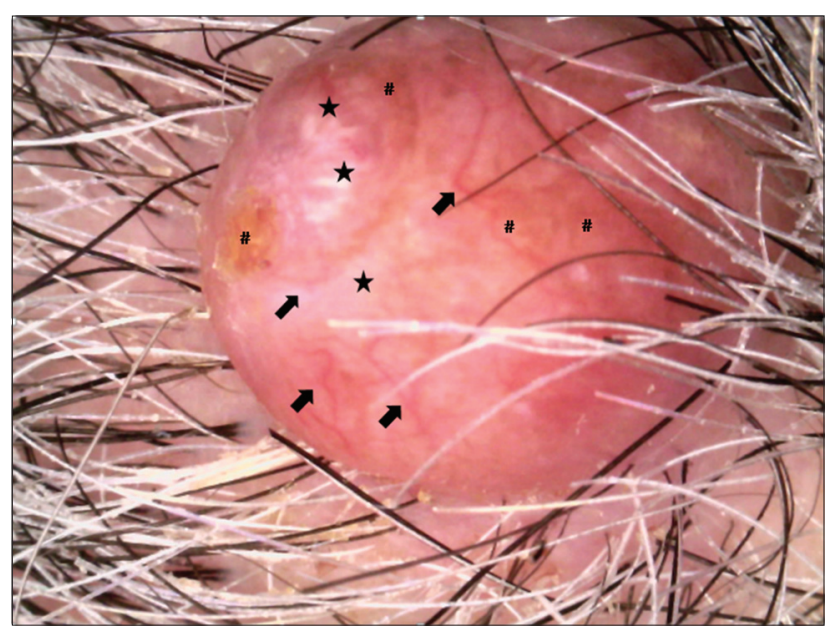

Figure 3: Dermoscopy image of nodular hidradenoma. Note white structures $\left({ }^{*}\right)$, pinkish and yellowish homogeneous areas(\#), linear irregular vessels and arborizing telangiectasias $(\rightarrow)$.

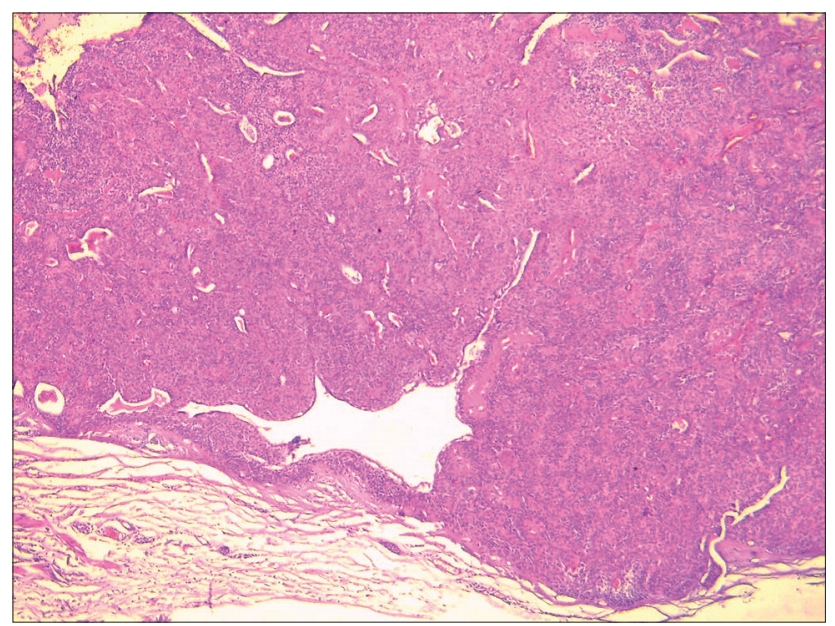

Figure 4: Low-power view of a circumscribed dermal tumor nodule Hex40.

involving the scalp, neck, trunk, and extremities [4]. Dermoscopy can be useful. Dermoscopic features include pinkish or bluish homogeneous areas with vascular and white structures [5]. Histological examination confirmed the diagnosis by showing a circumscribed but unencapsulated tumor composed of lobulated and cystic masses of cells mainly located in the upper or mid dermis [3]. The best treatment for

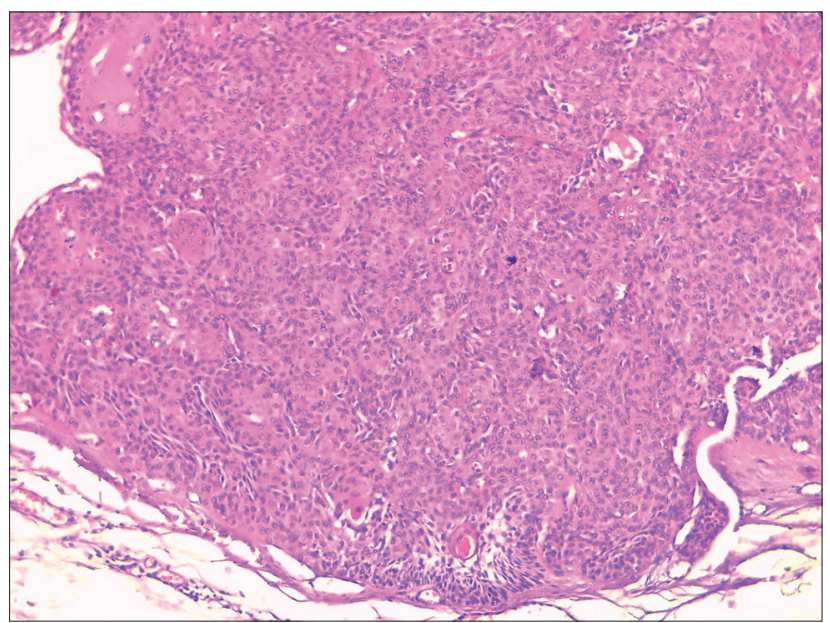

Figure 5: High-power view showing uniform cells with eosinophilic cytoplasm admixed with few clear cells HEx100.

$\mathrm{NH}$ is surgical excision. Although NH is a benign skin lesion, long term follow-up of patients is required to detect possible recurrence that may be transformed to malignant $\mathrm{NH}[6]$.

\section{REFERENCES}

1. Juan Carlos RM, Sylvia Aide MC, Alejandra VM, Ana Sofıa AC, Ivette MM, et al. Nodular hidradenoma: Dermoscopic presentation. J Am Acad Dermatol. 2017;76:S46-8.

2. Nasit JG, Dhruva G. Nodular hidradenoma of the scalp: A cytomorphologicalevaluation on fine needle aspiration cytology. Indian J Dermatol Venereol Leprol. 2014;80:569-72.

3. Abdulla AB, Suresh SR and Maragaret AR. Malignant nodular hidradenoma of the eyelid: a rare sweat gland tumor. Middle East Afr J Ophthalmol. 2010;17:374-6.

4. Kataria SP, Singh G, Batra A, Kumar S, Kumar V, Singh P. Nodular hidradenoma: aseries of five cases in male subjects and review of literature. Adv Cytol Pathol. 2018;3:46-7.

5. Patricia S, Aimilios L, Luis Javier DP, Isil K, Carolina M, et al. Dermoscopy of nodular hidradenoma, a great masquerader: a morphologicalstudy of 28 cases. Dermatology. 2016;232:78-82.

6. Nhuan N, Michiro S, Takahiro N, Yo K, Chiaki S, et al. Malignant transformation of nodular hidradenoma in the lower leg. Case Rep Oncol. 2018;11:298-304.

Copyright by Mohamed Ben Rejeb, et al. This is an open-access article distributed under the terms of the Creative Commons Attribution License, which permits unrestricted use, distribution, and reproduction in any medium, provided the original author and source are credited. Source of Support: Nil, Conflict of Interest: None declared. 